\title{
A collaborative approach to developing sustainable behaviour change interventions for childhood obesity prevention: Development of the Choosing Healthy Eating for Infant Health (CHErlsH) intervention and implementation strategy
}

Elaine Toomey ${ }^{*}$ (1), Karen Matvienko-Sikar ${ }^{2}$, Edel Doherty ${ }^{3}$, Janas Harrington ${ }^{2}$, Catherine B. Hayes ${ }^{4}$, Caroline Heary ${ }^{5}$, Marita Hennessy', Colette Kelly ${ }^{6}$, Sheena McHugh ${ }^{2}$, Jenny McSharry', Joanne O'Halloran ${ }^{7}$, Michelle Queally ${ }^{3}$, Tony Heffernan ${ }^{8}$, Patricia M. Kearney ${ }^{2}$ and Molly Byrne'

'Health Behavior Change Research Group, School of Psychology, National University of Ireland, Galway, Ireland

${ }^{2}$ School of Public Health, University College Cork, Ireland

${ }^{3}$ Discipline of Economics, National University of Ireland, Galway, Ireland

${ }^{4}$ Discipline of Public Health and Primary Care, Institute of Population Health, Trinity College Dublin, Ireland

${ }^{5}$ School of Psychology, National University of Ireland, Galway, Ireland

${ }^{6}$ Health Promotion Research Centre, School of Health Promotion, National University of Ireland, Galway, Ireland

${ }^{7}$ Primary Care Centre, Mountkennedy Town Centre, Co. Wicklow, Ireland

${ }^{8}$ Cork Road Clinic, Mallow Primary Healthcare Centre, Co. Cork, Ireland

Objectives and Design. There is growing recognition of the need for effective behaviour change interventions to prevent chronic diseases that are feasible and sustainable and can be implemented within routine health care systems. Focusing on implementation from the outset of intervention development, and incorporating multiple stakeholder perspectives to achieve this, is therefore essential. This study explores the development of the Choosing Healthy Eating for Infant Health (CHErlsH) childhood obesity prevention intervention and implementation strategy to improve infant feeding behaviours.

Methods. Five qualitative and quantitative evidence syntheses, two primary qualitative studies, and formal/informal consultations were conducted with practice, policy,

* Correspondence should be addressed to Elaine Toomey, Health Behaviour Change Research Group, School of Psychology, Arts Millennium Building, National University of Ireland Galway, Galway H9I TK33, Ireland (email: elaine.toomey@nuigalway.ie). $E T$ and KMS contributed equally to this manuscript and are joint first authors. 
research, and parent stakeholders. The Behaviour Change Wheel was used to guide the integration of findings.

Results. The CHErlsH intervention targets parent-level behaviour change and comprises (I) brief verbal messages and (2) trustworthy resources, to be delivered by health care professionals (HCPs) during routine infant vaccination visits. The implementation strategy targets HCP-level behaviour change and comprises (I) a local opinion leader, (2) incentivized training, (3) HCP resources and educational materials, (4) electronic delivery prompts, (5) awareness-raising across all primary care HCPs, and (6) local technical support.

Conclusions. This study provides a rigorous example of the development of an evidence-based intervention aimed at improving parental infant feeding behaviours, alongside an evidence-based behaviour change strategy to facilitate implementation and sustainability in primary care. This approach demonstrates how to systematically incorporate multiple stakeholder perspectives with existing literature and move from multiple evidence sources to clearly specified intervention components for both the intervention and implementation strategy.

\section{Statement of Contribution}

\section{What is already known?}

- Incorporating insights from practice, policy, and public/patient stakeholders plays a key role in developing behaviour change interventions that are feasible and sustainable and can be implemented within routine health care systems. However, there are limited examples that provide in-depth guidance of how to do this using a systematic approach.

\section{What this study adds?}

- This study describes an innovative use of the Behaviour Change Wheel to integrate multiple sources of evidence collected from practice, policy, research, and parent stakeholders to concurrently develop an evidence-based intervention to improve parental infant feeding behaviours and an implementation strategy to facilitate sustainable delivery by health care professionals in routine primary care

There is growing recognition of the need for effective evidence-based behaviour change interventions to prevent chronic diseases that are feasible and sustainable and can be implemented within routine health care systems (Brown \& Beardslee, 2016; Leslie et al., 2016; Walugembe, Sibbald, Le Ber, \& Kothari, 2019). It has been frequently stated that it can take up to 17 years for research evidence to become embedded within routine clinical practice (Grant, Green, \& Mason, 2003; Green, Ottoson, García, \& Hiatt, 2009; Morris, Wooding, \& Grant, 2011; Power et al., 2019), with many positing that this time-lag is compounded by a traditional step-wise approach from intervention development and feasibility testing, to efficacy and effectiveness evaluations, before finally moving to implementation (Brownson, Jacobs, Tabak, Hoehner, \& Stamatakis, 2013; Curran, Bauer, Mittman, Pyne, \& Stetler, 2012; Glasgow, Lichtenstein, \& Marcus, 2003). As such, it is of vital importance for interventions to be developed with a focus on implementation, and the multiple levels of behaviours required to facilitate implementation and intervention delivery, from the outset (Brownson et al., 2013; Chambers \& Norton, 2016; Pluye, Potvin, \& Denis, 2004; Schell et al., 2013). Incorporating insights from a variety of stakeholders including practice, policy, and 
patient/public enables several levels of behavioural factors influencing implementation to be considered, and has been consistently acknowledged as one of the most important aspects in developing sustainable public health interventions (Iwelunmor et al., 2016; Proctor et al., 2015; Schell et al., 2013; Stevens et al., 2017). However, incorporating multiple stakeholder perspectives within intervention development is not straightforward (Cottrell et al., 2014; Deverka et al., 2012). Few examples exist which explicitly detail how to integrate the perspectives of different stakeholders with existing evidence regarding intervention effectiveness and implementability, using a systematic and theoretically informed approach (Walugembe et al., 2019).

Incorporating stakeholder insights for developing sustainable interventions to prevent chronic diseases such as childhood obesity could be particularly beneficial. Childhood obesity is an urgent global concern with serious health, economic, and social implications both for the individual and the wider health system. Infancy and early childhood represent an optimal window to establish healthy behaviours and prevent the later development of childhood obesity and other chronic diseases (Safefood, 2018; Singh, Mulder, Twisk, van Mechelen, \& Chinapaw, 2008; Waters et al., 2011). In particular, ensuring optimum infant nutrition is vital, as a number of potentially modifiable infant feeding behaviours have been shown to predict later development of childhood overweight and obesity (Pluymen et al., 2018; Wang et al., 2016; Woo Baidal et al., 2016). These behaviours include the initiation and duration of breastfeeding as well as the introduction of solid foods (i.e., complementary feeding) (Birch \& Doub, 2014; Hurley, Cross, \& Hughes, 2011; PatroGołąb et al., 2016; Pearce \& Langley-Evans, 2013; Pluymen et al., 2018; Wang et al., 2016). International guidance from the World Health Organisation (WHO) recommends exclusive breastfeeding for the first six months of life, with complementary feeding (i.e., the introduction of nutritionally adequate and appropriate solid foods) from six months onwards (World Health Organisation, 2002). Despite these recommendations, a substantial proportion of infants worldwide are introduced to solid foods before four months (Barrera, Hamner, Perrine, \& Scanlon, 2018; Clayton, Li, Perrine, \& Scanlon, 2013; Inoue \& Binns, 2014; Schiess et al., 2010). Additionally, infants are commonly introduced to inappropriate foods that are high in energy, saturated fats, salt, and refined sugars or contain insufficient micronutrients (Inoue \& Binns, 2014; Tarrant, Younger, SheridanPereira, White, \& Kearney, 2010).

Childhood obesity prevention interventions delivered by health care professionals (HCPs) in primary care settings have been identified as particularly promising (Clayton et al., 2013; Matvienko-Sikar et al., 2018; McPherson, Mirkin, Heatherley, \& Homer, 2012). This is because primary care HCPs are a trusted source of information for parents (Bourgeois, Brauer, Simpson, Kim, \& Haines, 2016; Horodynski et al., 2007), and come into regular contact with parents during early infancy, such as during routine vaccination visits. However, the existing evidence for the effectiveness of infant feeding interventions to prevent childhood obesity, including those delivered by HCPs in health care contexts, is inconsistent (Blake-Lamb et al., 2016; Graziose, Downs, O'Brien, \& Fanzo, 2017; Hesketh \& Campbell, 2010; Laws et al., 2014; Matvienko-Sikar et al., 2018; Redsell, Edmonds, Swift, \& et al., 2016). Several systematic reviews have previously demonstrated variable effects of infant feeding interventions on both feeding and weight outcomes (Blake-Lamb et al., 2016; Graziose et al., 2017; Hesketh \& Campbell, 2010; Laws et al., 2014; Matvienko-Sikar et al., 2018; Redsell et al., 2016). However, these reviews identified a number of methodological flaws and quality issues within existing interventions, including poor application or use of behaviour change theory (Hesketh \& Campbell, 2010; Matvienko-Sikar et al., 2019; Redsell et al., 2016), a 
lack of systematic approach to intervention development (Graziose et al., 2017), significant heterogeneity in outcome measurement and reporting (Laws et al., 2014; Matvienko-Sikar et al., 2018), and an insufficient focus on the internal and external validity of the intervention (e.g., intervention fidelity delivery and adherence) (Redsell et al., 2016; Toomey et al., 2018). Overall, the findings of these reviews suggested that multi-component interventions underpinned by theory that incorporate a responsive feeding focus may have the most potential to impact on feeding and weight outcomes (Blake-Lamb et al., 2016; Graziose et al., 2017; Hesketh \& Campbell, 2010; Laws et al., 2014; Matvienko-Sikar et al., 2018; Redsell et al., 2016). The reviews also highlighted a limited focus on implementation and long-term sustainability, and a need for future research to develop multi-level behaviour change interventions that target beyond the individual/family level alone, and that can be embedded into routine service delivery (Blake-Lamb et al., 2016; Graziose et al., 2017; Laws et al., 2014; Redsell et al., 2016; Waters et al., 2011). As such, there is a clear need to develop evidence-based behaviour change interventions that integrate research evidence with multiple stakeholder views and contextual information to facilitate implementation and sustainability within existing health care settings.

The aim of this study was to systematically develop an evidence-based intervention to improve parental infant feeding behaviours, and a concurrent evidence-based implementation strategy targeting HCP behaviours to support and sustain intervention delivery during routine vaccination visits. The Behaviour Change Wheel (BCW) intervention development framework (Michie, van Stralen, \& West, 2011) was used to structure this approach and to incorporate evidence and insights from practice, policy, and parents.

\section{Methods}

\section{Intervention context}

In Ireland, vaccinations are delivered at five standardized time-points $(2,4,6,12$, and 13 months) within the Health Service Executive (HSE) National Healthy Childhood Programme, a free universal child health service that is available from pregnancy through to adolescence ('HSE Healthy Childhood Programme,'). The Nurture Programme is a recently established quality improvement initiative within the National Healthy Childhood Programme that aims to support, empower, and educate parents and practitioners on a variety of infant health and well-being topics, including nutrition ('HSE Nurture Programme - Infant Health and Wellbeing,').

\section{Sources of evidence}

The Choosing Healthy Eating for Infant Health (CHErIsH) team comprises researchers with expertise in a variety of areas including childhood obesity, population/public health, infant nutrition, developmental psychology, epidemiology, health psychology, health promotion, health services research, behaviour change, primary care, health economics, and implementation science (ET, KMS, JMS, SMH, PK, ED, JH, CH, CHe, MH, CK, JOH, MQ, $\mathrm{TH}, \mathrm{MB}$ ). We (the CHErIsH team) conducted five evidence syntheses and two primary qualitative studies with HCPs and parents, as well as formal and informal consultations with policy, practice, and researcher stakeholders (full details of sources in Table 1). We combined findings from these sources in an iterative process to inform each step of the BCW framework and guide final decision-making made by our interdisciplinary research team. 
Table I. CHErIsH sources of evidence for intervention development

\begin{tabular}{|c|c|c|c|}
\hline $\begin{array}{l}\text { Source code: Source title } \\
\text { (reference) }\end{array}$ & $\begin{array}{l}\text { Type of } \\
\text { activity }\end{array}$ & $\begin{array}{l}\text { Overview of source aims } \\
\text { and findings }\end{array}$ & $\begin{array}{l}\text { Behaviour Change } \\
\text { Wheel phase(s) and } \\
\text { step(s) informed }\end{array}$ \\
\hline $\begin{array}{l}\text { SRI: 'Effects of health care } \\
\text { professional delivered } \\
\text { early feeding interventions } \\
\text { on } \\
\text { feeding practices and } \\
\text { dietary intake: A } \\
\text { systematic review' } \\
\text { (Matvienko-Sikar } \\
\text { et al., 20I8) }\end{array}$ & $\begin{array}{l}\text { Systematic } \\
\text { review }\end{array}$ & $\begin{array}{l}\text { - Aimed to evaluate the } \\
\text { effects of health care pro- } \\
\text { fessional (HCP) delivered } \\
\text { infant feeding interven- } \\
\text { tions, delivered in the first } \\
\text { two years postpartum on } \\
\text { parental feeding practices, } \\
\text { dietary intake, and weight } \\
\text { outcomes for children. } \\
\text { - } 10 \text { trials of interventions } \\
\text { demonstrated inconsistent } \\
\text { effects on feeding practices, } \\
\text { dietary intake, and weight } \\
\text { outcomes. Findings } \\
\text { showed some reductions in } \\
\text { pressure to eat and infant } \\
\text { consumption of non-core } \\
\text { beverages. } \\
\text { - Responsive feeding-based } \\
\text { interventions demon- } \\
\text { strated greater improve- } \\
\text { ments in feeding } \\
\text { approaches, and weight } \\
\text { outcomes }\end{array}$ & $\begin{array}{l}\text { Phase I: Steps 2, 3, } 4 \\
\text { Phase 2: Step } 5 \\
\text { Phase 3: Step } 8\end{array}$ \\
\hline $\begin{array}{l}\text { SR2: 'Intervention Fidelity } \\
\text { Within Trials of Infant } \\
\text { Feeding Behavioural } \\
\text { Interventions to } \\
\text { Prevent Childhood } \\
\text { Obesity: A Systematic } \\
\text { Review' (Toomey } \\
\text { et al., 2018) }\end{array}$ & $\begin{array}{l}\text { Systematic } \\
\text { review }\end{array}$ & $\begin{array}{l}\text { - Aimed to explore the use } \\
\text { and/or reporting of strate- } \\
\text { gies to enhance and assess } \\
\text { intervention fidelity within } \\
\text { I0 trials (identified in SR I) } \\
\text { of HCP-delivered infant } \\
\text { feeding interventions, using } \\
\text { the National Institutes of } \\
\text { Health Behaviour Change } \\
\text { Consortium (Borrelli et al., } \\
\text { 2005) fidelity checklist. } \\
\text { - Average use/reporting of } \\
\text { fidelity strategies was } \\
\text { moderate } \\
\text { - Highlighted the need to } \\
\text { improve reporting of } \\
\text { intervention fidelity strate- } \\
\text { gies and ensure focus on } \\
\text { HCP-level behaviour } \\
\text { change. }\end{array}$ & $\begin{array}{l}\text { Phase I: Steps 2, } 4 \\
\text { Phase 2: Step } 5 \\
\text { Phase 3: Step } 8\end{array}$ \\
\hline
\end{tabular}


Table I. (Continued)

\begin{tabular}{|c|c|c|c|}
\hline $\begin{array}{l}\text { Source code: Source title } \\
\text { (reference) }\end{array}$ & $\begin{array}{l}\text { Type of } \\
\text { activity }\end{array}$ & $\begin{array}{l}\text { Overview of source aims } \\
\text { and findings }\end{array}$ & $\begin{array}{l}\text { Behaviour Change } \\
\text { Wheel phase (s) and } \\
\text { step(s) informed }\end{array}$ \\
\hline $\begin{array}{l}\text { SR3: 'Behaviour Change } \\
\text { Techniques and Theory } \\
\text { Use in Healthcare } \\
\text { Professional-Delivered } \\
\text { Early Feeding Interventions } \\
\text { to Prevent Childhood } \\
\text { Obesity: A Systematic } \\
\text { Review' (Matvienko-Sikar } \\
\text { et al., 2019) }\end{array}$ & $\begin{array}{l}\text { Systematic } \\
\text { review }\end{array}$ & $\begin{array}{l}\text { - Aimed to evaluate the use } \\
\text { of behaviour change tech- } \\
\text { niques and psychological } \\
\text { theory in HCP-delivered } \\
\text { infant feeding interventions } \\
\text { for children } \leq 2 \text { years. } \\
\text { - I } 2 \text { trials were examined } \\
\text { using the Behaviour } \\
\text { Change Technique (BCT) } \\
\text { Taxonomy vl (Michie et al., } \\
\text { 20I3) and the Theory } \\
\text { Coding Scheme (Michie \& } \\
\text { Prestwich, } 20 \text { I0). } \\
\text { Theory use was poor; most } \\
\text { commonly used theories } \\
\text { were social cognitive the- } \\
\text { ory (SCT) ( } n=4 \text { studies) } \\
\text { and responsive feeding } \\
(n=4) \text {. Studies that incor- } \\
\text { porated theory in inter- } \\
\text { vention development and } \\
\text { evaluation demonstrated } \\
\text { better child weight out- } \\
\text { comes. } \\
\text { - Highlighted need for ade- } \\
\text { quate integration of theory } \\
\text { in intervention develop- } \\
\text { ment, and identified BCTs } \\
\text { that had been used in more } \\
\text { effective interventions. }\end{array}$ & $\begin{array}{l}\text { Phase I: Steps 3, } 4 \\
\text { Phase 2: Step } 5 \\
\text { Phase 3: Steps 7, } 8\end{array}$ \\
\hline $\begin{array}{l}\text { QESI: 'Parental experiences } \\
\text { and perceptions of infant } \\
\text { complementary feeding: a } \\
\text { qualitative evidence } \\
\text { synthesis' (Matvienko- } \\
\text { Sikar et al., 2018) }\end{array}$ & $\begin{array}{r}\text { Qualitative } \\
\text { evidence } \\
\text { synthesis }\end{array}$ & $\begin{array}{l}\text { - Aimed to explore parents' } \\
\text { perceptions and experi- } \\
\text { ences of infant feeding and } \\
\text { complementary feeding } \\
\text { recommendations. } \\
\text { - } 25 \text { qualitative studies } \\
\text { included } \\
\text { - Four key themes were } \\
\text { identified: I) 'Guidelines } \\
\text { and advice' related to the } \\
\text { variety and inconsistencies } \\
\text { between sources of feeding } \\
\text { information, 2) 'Stage of } \\
\text { weaning' related to infant } \\
\text { feeding as a process }\end{array}$ & $\begin{array}{l}\text { Phase I: Steps 2, 3, } 4 \\
\text { Phase 2: Step 5 } \\
\text { Phase 3: Steps 7, } 8\end{array}$ \\
\hline
\end{tabular}


Table I. (Continued)

\begin{tabular}{|c|c|c|c|}
\hline $\begin{array}{l}\text { Source code: Source title } \\
\text { (reference) }\end{array}$ & $\begin{array}{l}\text { Type of } \\
\text { activity }\end{array}$ & $\begin{array}{l}\text { Overview of source aims } \\
\text { and findings }\end{array}$ & $\begin{array}{l}\text { Behaviour Change } \\
\text { Wheel phase(s) and } \\
\text { step(s) informed }\end{array}$ \\
\hline $\begin{array}{l}\text { QES2: 'Health-care } \\
\text { professional and parental } \\
\text { views and experiences of } \\
\text { implementing infant } \\
\text { feeding interventions: a } \\
\text { qualitative evidence } \\
\text { synthesis' (E. Toomey, } \\
\text { M. Byrne, C. Houghton, } \\
\text { C. Kelly, K. Matvienko- } \\
\text { Sikar, J. Mc Sharry, } \\
\text { M. Queally, E. Doherty, } \\
\text { C. Hayes, M. Hennessy, } \\
\text { S. McHugh, P.M. Kearney, } \\
\text { \& C. Heary on behalf of the } \\
\text { Choosing Healthy Eating } \\
\text { for Infant Health } \\
\text { [CHErlsH] study team, in } \\
\text { preparation) }\end{array}$ & $\begin{array}{c}\text { Qualitative } \\
\text { evidence } \\
\text { synthesis }\end{array}$ & 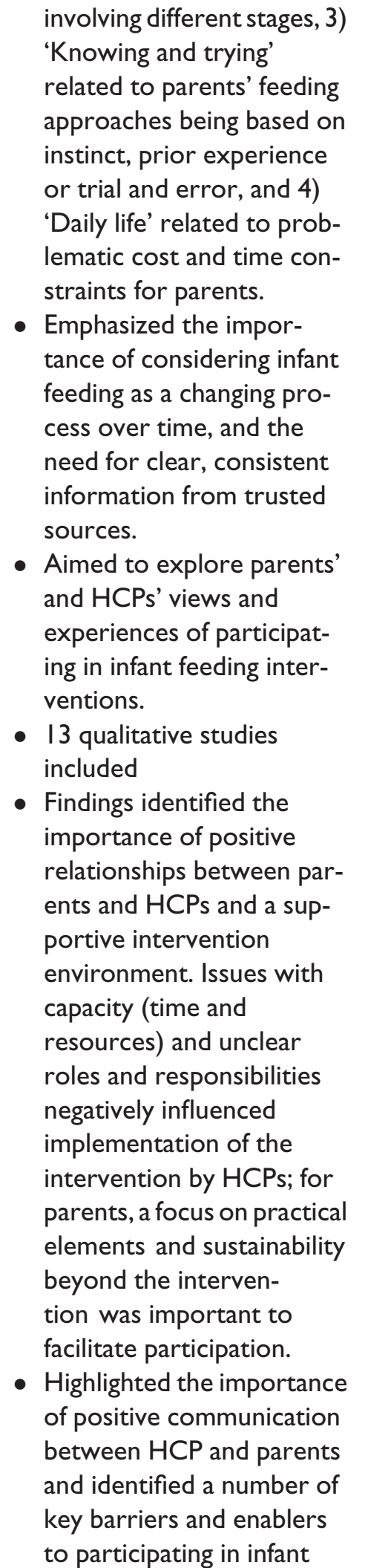 & $\begin{array}{l}\text { Phase I: Steps 2, } 4 \\
\text { Phase 2: Step } 5 \\
\text { Phase 3: Step } 8\end{array}$ \\
\hline
\end{tabular}


Table I. (Continued)

\begin{tabular}{|c|c|c|c|}
\hline $\begin{array}{l}\text { Source code: Source title } \\
\text { (reference) }\end{array}$ & $\begin{array}{l}\text { Type of } \\
\text { activity }\end{array}$ & $\begin{array}{l}\text { Overview of source aims } \\
\text { and findings }\end{array}$ & $\begin{array}{l}\text { Behaviour Change } \\
\text { Wheel phase(s) and } \\
\text { step(s) informed }\end{array}$ \\
\hline $\begin{array}{l}\text { FG: 'Experience and } \\
\text { perceptions of infant } \\
\text { feeding and delivery of an } \\
\text { infant feeding intervention } \\
\text { in primary care in Ireland' } \\
\text { (C. Flannery, K. } \\
\text { Matvienko-Sikar, E. } \\
\text { Toomey, C. Kelly, M. } \\
\text { Byrne, C. Heary, S. } \\
\text { McHugh, \& M. Hennessy, in } \\
\text { preparation) }\end{array}$ & $\begin{array}{l}\text { Qualitative } \\
\text { focus } \\
\text { groups }\end{array}$ & $\begin{array}{l}\text { feeding interventions for } \\
\text { both parents and HCPs. } \\
\text { - Aimed to explore views on } \\
\text { engaging in healthy infant } \\
\text { feeding practices, partici- } \\
\text { pation in infant feeding } \\
\text { interventions and opinions } \\
\text { of proposed intervention } \\
\text { - Six focus groups with } 30 \\
\text { parents (mothers and } \\
\text { fathers) } \\
\text { - Findings identified that } \\
\text { importance of clear and } \\
\text { consistent messages, and } \\
\text { practical guidance and sup- } \\
\text { port delivered at the right } \\
\text { time, and the importance of } \\
\text { trustworthiness of the } \\
\text { intervention and associated } \\
\text { resources, and relation- } \\
\text { ships with HCPs } \\
\text { - Parents have different } \\
\text { preferences in terms of the } \\
\text { format of intervention and } \\
\text { information delivery, but } \\
\text { were mostly positive about } \\
\text { the potential for using the } \\
\text { vaccination visits as a } \\
\text { potential time-point }\end{array}$ & $\begin{array}{l}\text { Phase I: Steps 2, 3, } 4 \\
\text { Phase 2: Step } 5 \\
\text { Phase 3: Steps 7, } 8\end{array}$ \\
\hline $\begin{array}{l}\text { QI: 'Exploring infant feeding } \\
\text { interventions in primary } \\
\text { care with healthcare } \\
\text { professionals: a qualitative } \\
\text { interview study', (E. } \\
\text { Toomey, M. Byrne, C. } \\
\text { Houghton, C. Kelly, K. } \\
\text { Matvienko-Sikar, J. Mc } \\
\text { Sharry, M. Queally, E. } \\
\text { Doherty, C. Hayes, M. } \\
\text { Hennessy, S. McHugh, P.M. } \\
\text { Kearney, \& C.Heary on } \\
\text { behalf of the Choosing } \\
\text { Healthy Eating for Infant } \\
\text { Health [CHErlsH] study } \\
\text { team, in preparation) }\end{array}$ & $\begin{array}{l}\text { Qualitative semi- } \\
\text { structured } \\
\text { interviews }\end{array}$ & $\begin{array}{l}\text { - Aimed to explore HCP } \\
\text { views on addressing infant } \\
\text { feeding in primary care, and } \\
\text { the potential barriers and } \\
\text { enablers to the use of brief } \\
\text { vaccination visits as a time- } \\
\text { point for intervention } \\
\text { delivery } \\
\text { - } 2 \text { I semi-structured inter- } \\
\text { views with primary care } \\
\text { HCPs ( } 5 \text { practice nurses, } 7 \\
\text { general practitioners, } 3 \\
\text { public health nurses, } 3 \\
\text { community dieticians, and } 3 \\
\text { community medical officers) }\end{array}$ & $\begin{array}{l}\text { Phase I: Steps 2, 3, } 4 \\
\text { Phase 2: Step } 5 \\
\text { Phase 3: Steps 7, } 8\end{array}$ \\
\hline
\end{tabular}


Table I. (Continued)

\begin{tabular}{|c|c|c|c|}
\hline $\begin{array}{l}\text { Source code: Source title } \\
\text { (reference) }\end{array}$ & $\begin{array}{l}\text { Type of } \\
\text { activity }\end{array}$ & $\begin{array}{l}\text { Overview of source aims } \\
\text { and findings }\end{array}$ & $\begin{array}{l}\text { Behaviour Change } \\
\text { Wheel phase(s) and } \\
\text { step(s) informed }\end{array}$ \\
\hline $\begin{array}{l}\text { IC: Informal consultations } \\
\text { with local and national } \\
\text { infant feeding policy and } \\
\text { practice representatives }\end{array}$ & $\begin{array}{l}\text { Informal } \\
\text { consultations }\end{array}$ & $\begin{array}{l}\text { - Highlighted importance of } \\
\text { consistency regarding } \\
\text { infant feeding messages, } \\
\text { trustworthy resources for } \\
\text { both parents and HCPs, } \\
\text { and a need to support } \\
\text { practical skill development } \\
\text { for parents } \\
\text { Barriers included a lack of } \\
\text { time/capacity, resources, } \\
\text { insufficient clarity regarding } \\
\text { HCP roles and potential } \\
\text { parent/child stress at the } \\
\text { time of vaccinations } \\
\text { - Enablers included the } \\
\text { importance of the topic, } \\
\text { good relationships } \\
\text { between parents and pri- } \\
\text { mary care HCPs, and the } \\
\text { fact that children present- } \\
\text { ing for vaccination visits are } \\
\text { typically medically well } \\
\text { - Vaccination visits were } \\
\text { found to be potentially fea- } \\
\text { sible if those barriers and } \\
\text { enablers were taken into } \\
\text { consideration } \\
\text { - Aimed to provide insight } \\
\text { and information about the } \\
\text { intervention context from } \\
\text { a policy and practice per- } \\
\text { spective } \\
\text { - Separate informal consul- } \\
\text { tations were held with pol- } \\
\text { icy representatives from } \\
\text { the Health Service Execu- } \\
\text { tive National Healthy } \\
\text { Childhood Programme (3 } \\
\text { face-to-face meetings and } \\
\text { ongoing email/telephone } \\
\text { contact) and a practice- } \\
\text { based general practitioner } \\
\text { (TH) (6 face-to-face meet- } \\
\text { ings and ongoing telephone } \\
\text { contacts) }\end{array}$ & $\begin{array}{l}\text { Phase I: Steps 2, } 3 \\
\text { Phase 2: Step } 5 \\
\text { Phase 3: Steps 7, } 8\end{array}$ \\
\hline
\end{tabular}


Table I. (Continued)

\begin{tabular}{|c|c|c|c|}
\hline $\begin{array}{l}\text { Source code: Source title } \\
\text { (reference) }\end{array}$ & $\begin{array}{l}\text { Type of } \\
\text { activity }\end{array}$ & $\begin{array}{l}\text { Overview of source aims } \\
\text { and findings }\end{array}$ & $\begin{array}{l}\text { Behaviour Change } \\
\text { Wheel phase(s) and } \\
\text { step(s) informed }\end{array}$ \\
\hline $\begin{array}{l}\text { ISC: International steering } \\
\text { committee expert meeting }\end{array}$ & $\begin{array}{l}\text { International } \\
\text { steering } \\
\text { committee } \\
\text { meeting }\end{array}$ & 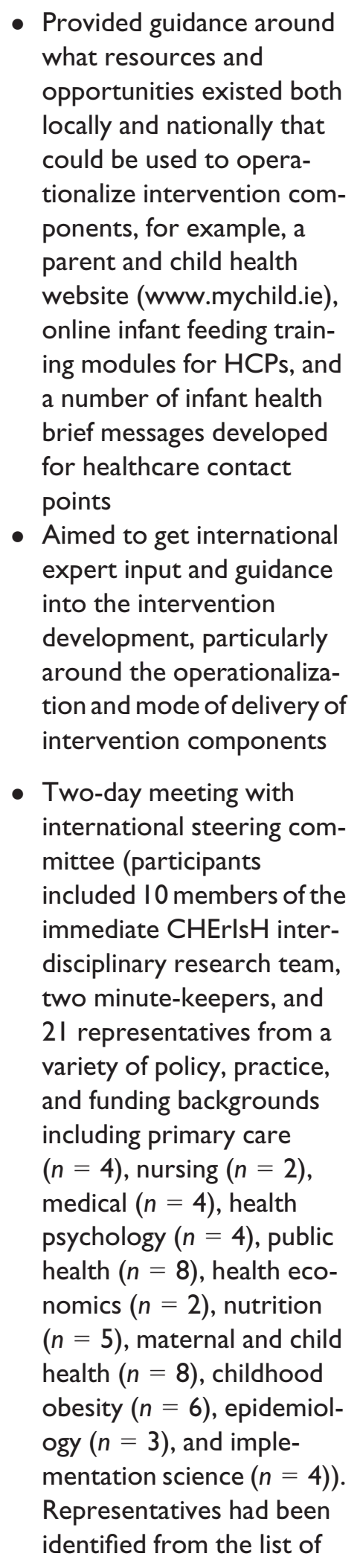 & Phase 3: Step 8 \\
\hline
\end{tabular}


Table I. (Continued)

\begin{tabular}{|c|c|c|c|}
\hline $\begin{array}{l}\text { Source code: Source title } \\
\text { (reference) }\end{array}$ & $\begin{array}{l}\text { Type of } \\
\text { activity }\end{array}$ & $\begin{array}{l}\text { Overview of source aims } \\
\text { and findings }\end{array}$ & $\begin{array}{l}\text { Behaviour Change } \\
\text { Wheel phase(s) and } \\
\text { step(s) informed }\end{array}$ \\
\hline & & $\begin{array}{l}\text { original project application } \\
\text { collaborators and also } \\
\text { through word of mouth or } \\
\text { existing networks. Local } \\
\text { practice and national policy } \\
\text { representatives (IC) were } \\
\text { also present. } \\
\text { - Three recommendations } \\
\text { were made regarding: I) } \\
\text { the involvement of primary } \\
\text { care HCPs beyond those } \\
\text { who would be delivering } \\
\text { the intervention, 2) the } \\
\text { need for HCP training, and } \\
\text { 3) the degree of flexibilityl } \\
\text { tailoring permitted regard- } \\
\text { ing intervention content }\end{array}$ & \\
\hline
\end{tabular}

$\mathrm{SR}=$ systematic review, $\mathrm{QES}=$ qualitative evidence synthesis, $\mathrm{FG}=$ focus groups, $\mathrm{Q}$ I = qualitative interviews, IC = informal consultations, ISC = international steering committee, $\mathrm{HCP}=$ health care professional.

\section{Applying the behaviour change wheel approach}

The BCW approach (Michie, Atkins, \& West, 2014) outlines three phases with eight specific steps across these phases.

\section{Phase I: Understanding the behaviour}

Phase 1 comprises the following: Step 1 (defining the problem in behavioural terms), Step 2 (selecting the target behaviour(s)), Step 3 (specifying the target behaviour(s)), and Step 4 (identifying what needs to change). Specifically, this phase involves identifying components of the target behaviour (who, what, where, when, and bow often) to be addressed through the intervention using the COM-B (Capability, Opportunity, Motivation-Behaviour) model. The COM-B model recognizes that for a person to change their behaviour, they must have the physical and psychological capability, social and physical opportunity, and reflective and automatic motivation (Michie et al., 2011).

We used existing data regarding current infant feeding practices and introduction of solid foods (Bennett, 2017; Castro, Kearney, \& Layte, 2015; safefood, 2018; Tarrant et al. 2010) to understand and define the problem in behavioural terms. Selection and specification of the parental behaviours relevant to improving infant feeding, as well as the HCP behaviours needed to facilitate these behaviours in the intended primary care vaccination visit setting, were achieved by exploring national and international infant feeding recommendations (Fewtrell et al., 2017; Food Safety Authority of Ireland, 2011; Health Service Executive, 2016; Healthy Ireland, 2015; World Health Organisation, 2002) 
in conjunction with findings from our evidence sources (Table 1). Our informal consultations with local and national infant feeding policy and practice representatives provided valuable insight in terms of which particular behaviours might be best to target within the current Irish primary care context.

Specific barriers and enablers to the targeted parent-level behaviours and HCP/ practice-level behaviours were extracted from our parent focus groups (FG) and HCP interviews (QI) and subsequently triangulated with findings of the evidence syntheses (SR1, SR2, SR3, QES1, QES2) by two authors. One author conducted initial coding, with $100 \%$ of this coding double-checked and verified separately by a second author. Specifically, parent-level barriers/enablers were coded according to the COM-B by KMS and HCP-level barriers/enablers were coded by ET, with each analysis verified by the other coder.

\section{Phase 2: Identify intervention options}

Phase 2 applies the BCW framework guidance (Michie et al., 2014) to choose potential intervention options based on the findings of Phase 1. Specifically, Step 5 identifies intervention functions or the 'broad categories of means by which an intervention can change behaviour' (Michie et al., 2014) (e.g., Education, Training), which map onto the relevant COM-B components identified in Phase 1. Where multiple options for intervention functions exist, the APEASE (Affordability, Practicability, Effectiveness/ cost-effectiveness, Acceptability, Side effects/Safety, Equity) criteria (Michie et al., 2014) can be used to determine the most appropriate option. Step 6 involves identifying specific policy-related areas to target (Michie et al., 2011). This project focused on parent and practitioner-level change, and changing policy was deemed outside of the scope; therefore, this step was not included within our project.

For Step 5, two authors used a template to facilitate application of the APEASE criteria in a standardized manner for both the parent behaviours and the targeted HCP behaviours (File S1). Using information from four of our evidence syntheses (QES1, QES2, SR1, SR3) and qualitative data collection with parents and HCPs (QI, FG), ET and KMS collectively applied the APEASE criteria to each BCW intervention function via consensus discussion, with rationale for each decision documented on the template. Functions that met all APEASE criteria were included.

\section{Phase 3: Identify content and implementation options}

Phase 3 involves explicit identification of the intervention content in terms of behaviour change techniques (BCTs) (Step 7). BCTs are observable, replicable, and irreducible active ingredients of an intervention designed to change behaviour, and are listed and defined within the BCT Taxonomy v1 (BCTTv1) (Michie et al., 2013). Finally, Step 8 involves operationalizing each BCT, that is, translating the BCT from its taxonomy definition into a concrete application of what it would look like within an intervention.

To inform the selection of final BCTs, using a similar process as outlined for identifying intervention functions, two authors (ET, KMS) collectively applied the APEASE criteria to each possible BCT via consensus discussion. Guided by the findings of our evidence syntheses (SR1, SR2, SR3, QES1, QES2) and qualitative data collection with parents and HCPs (FG, QI), we (ET, KMS) brainstormed potential intervention components and modes of delivery. We then presented the options to our international expert steering committee, practice, and policy representatives for feedback to guide final decision- 
making by the CHErIsH team. Key recommendations arising from the international steering committee were documented and subsequently reviewed by the CHErIsH team at a follow-up meeting. As with each previous step of the process, consensus was reached on the finalized intervention and implementation strategy via discussion within the CHErIsH study team.

\section{Results}

\section{Phase I: Understanding the behaviour}

Step I: Define the problem in behavioural terms

As outlined in the introduction, a substantial proportion of infants internationally are introduced to inappropriate foods before the recommended time (Castro et al., 2015; Inoue \& Binns, 2014; O'Donovan et al., 2015; Tarrant et al., 2010). We therefore defined the problem in behavioural terms as the practice of suboptimal infant feeding behaviours by parents of infants aged $0-2$.

Step 2: Selecting the target behaviour(s)

A number of specific parental behaviours relevant to the broader target of improving healthy infant feeding behaviours were identified from existing infant feeding recommendations (Food Safety Authority of Ireland, 2011; Healthy Ireland, 2015; World Health Organisation, 2002), which included guidance on maternal nutrition and physical activityrelated behaviours before and during pregnancy, breastfeeding, and formula-feeding behaviours, as well as the timing of introduction of solid foods, the types and stages of solid foods introduced, and the ways in which parents feed their babies in response to infant cues (i.e., responsive feeding). Although several behaviours were relevant to our area of interest, we decided to focus predominantly on the introduction and provision of solid foods to children aged between 0 and 2, and in particular to select three core behaviours relating to (1) the timing of solid food introduction, (2) progression through the stages and textures of solid foods, and (3) responsive feeding behaviours. This decision was influenced by findings from our evidence sources (Table 1). Specifically, our systematic review of effectiveness (SR1) identified that interventions based on responsive feeding theory demonstrated greater improvements in feeding approaches and weight outcomes. Our qualitative data collection (FG, QI) also reinforced the importance of developing parental skills such as responding to infant cues. In addition, our qualitative evidence synthesis of parents' experiences of complementary feeding (QES1) and our focus groups (FG) both emphasized the importance of considering infant feeding as a changing process over time involving different stages.

In terms of selecting HCP behaviours for our implementation strategy, the findings of our systematic review of intervention fidelity (SR2) identified the importance of an explicit focus on HCP training and behaviour change within these types of interventions. In addition, our interviews with health care professionals (QI) and our qualitative evidence synthesis of parents' and HCPs' perspectives of infant feeding interventions (QES2) emphasized issues relating to capacity and resources for HCPs. Drawing on this evidence, in conjunction with informal consultations with our policy and practice-based representatives, we decided to select the provision of guideline-based information and support for the introduction of solid foods in primary care by HCPs involved in the vaccination visits as the HCP-level behavioural target. 
Step 3: Specifying the target behaviour(s)

We specified our parent-level behaviours to be that parents (who) would (1) wait until as close to 26 weeks as possible to introduce solids and not before 17 weeks, (2) feed nutritious and developmentally appropriate foods, and (3) respond appropriately to the infant's hunger and satiety cues (what) each and every time they fed their infant (when, where, and bow often). This specification was informed by integrating national and international guidelines (Fewtrell et al., 2017; Food Safety Authority of Ireland, 2011; Health Service Executive, 2016; Healthy Ireland, 2015; World Health Organisation, 2002) with findings from our qualitative evidence synthesis of parents' views of infant feeding (QES1), our systematic reviews of effectiveness (SR1) and behaviour change theory and techniques (SR3) and our focus groups with parents (FG) in conjunction with consultation with the policy representatives.

For the HCP-level behaviour, that is, the provision of guideline-based information and support for introduction of solid foods at vaccination visits, our HCP interviews (QI), in addition to our informal policy and practice consultations, provided us with the contextual knowledge needed to identify the specifics of this behaviour. For example, both sources informed us that vaccinations in Ireland are typically delivered by practice nurses, but may occasionally be delivered by general practitioners in certain circumstances. Our interviews with HCPs also informed us that potentially the most acceptable time to deliver information alongside vaccination visits would be before the vaccine itself was administered. We therefore specified our HCP-level behaviour to be that practice nurses and/or general practitioners ( $w h o$ ) would provide guideline-based information and support for introduction of solid foods (what) just before the delivery of vaccinations (when) in the practice vaccination room (where), at the 2-, 4-, 6-, 12-, and 13-month vaccination visits (bow often).

Step 4: Identify what needs to change

The identified barriers and enablers to the target behaviours and to conducting the intervention within vaccination visits, analysed according to the COM-B model, are presented in Table 2 .

\section{Phase 2: Identify intervention options}

\section{Step 5: Identify intervention functions}

All nine $\mathrm{BCW}$ intervention functions were potentially relevant to the COM-B components identified in Step 4 for both the parent behaviour and the targeted HCP behaviour. By using our evidence sources to inform how we applied the APEASE criteria, we selected three intervention functions (Education, Environmental restructuring, and Persuasion) to address the parent-level targeted behaviour. For example, 'Education' was identified as relevant within four of our evidence syntheses (QES1, QES2, SR1, SR3) and our qualitative data collection with parents and HCPs (QI, FG). Using the information gleaned from these studies, we deemed the provision of education for parents to be Affordable, Practicable, potentially Effective and Cost-effective, Acceptable, Safe, and Equitable. In a similar manner, we selected Training, Education, Environmental restructuring, Persuasion, Incentivization, and Modelling as the intervention functions to address the HCP-level targeted behaviour (Table 2). The APEASE criteria ratings and the rationale for each intervention function selected for both the intervention and implementation strategy are provided in File S1. 


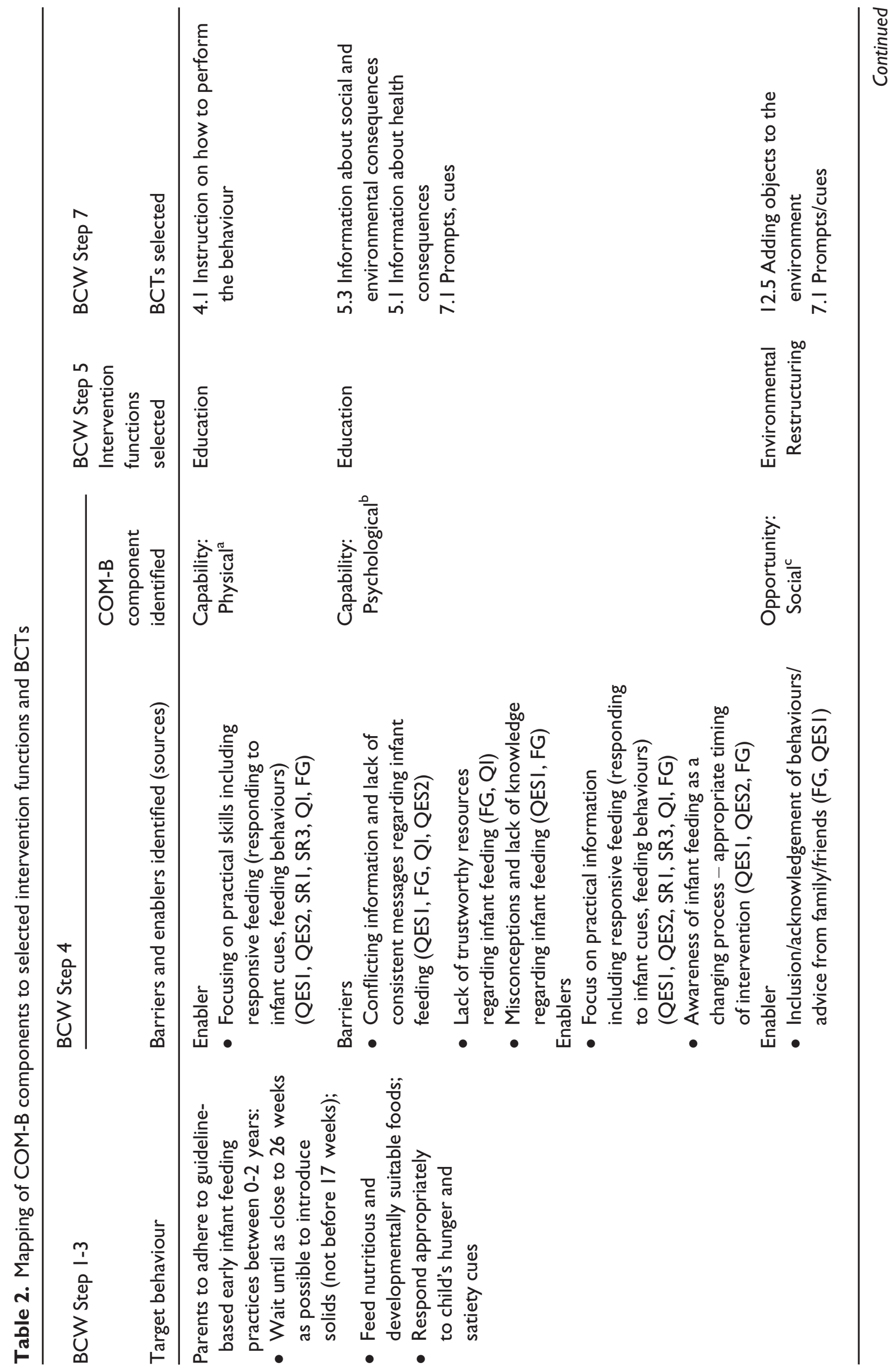




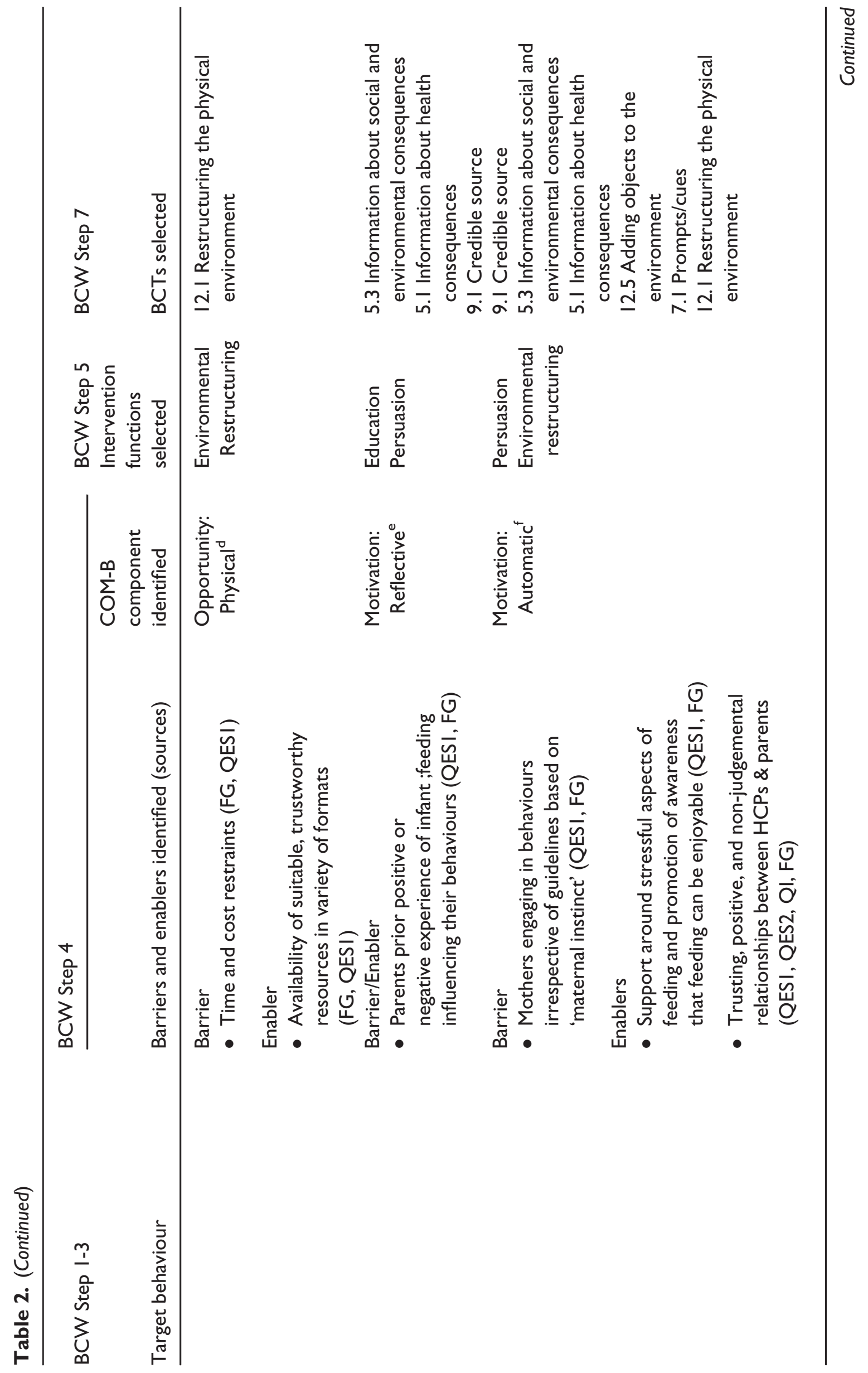




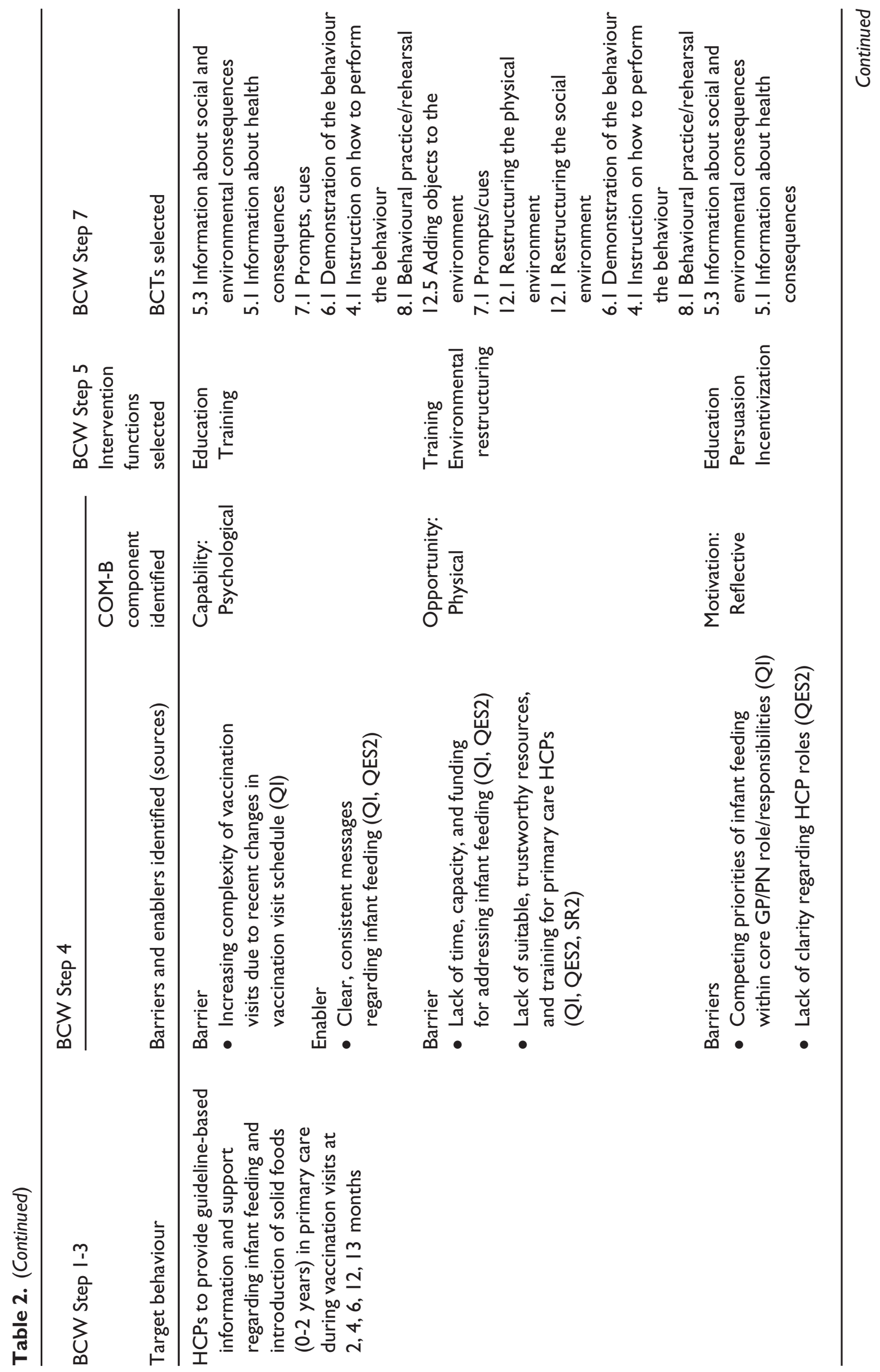




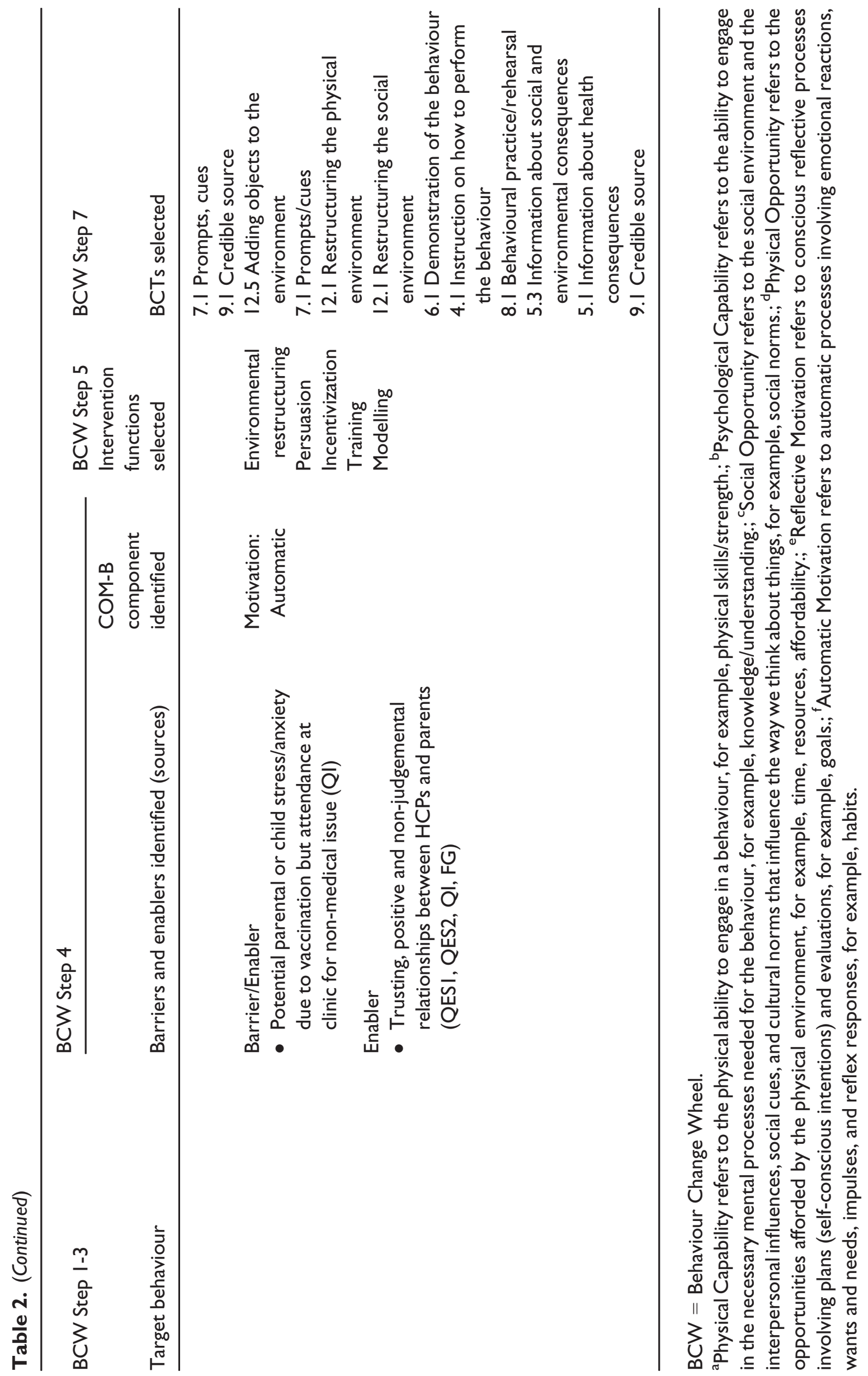


Table 3. Operationalization of selected BCTs and modes of delivery within $\mathrm{CHErlsH}$ intervention

\begin{tabular}{|c|c|}
\hline BCT selected in Step 7 & $\begin{array}{l}\text { Operationalization of BCTs and modes of delivery } \\
\text { within } \mathrm{CHErIsH}\end{array}$ \\
\hline $\begin{array}{l}\text { Parent behaviour }{ }^{\mathrm{a}} \\
\text { Instruction on how to } \\
\text { perform behaviour (4.I) }\end{array}$ & $\begin{array}{l}\text { - HCP to advise parents on how to perform the behaviour } \\
\text { using brief verbal messages tailored for each vaccination } \\
\text { time-point }(2,4,6,12 \text {, and I } 3 \text { months) } \\
\text { o Brief verbal messages to be developed using existing HSE } \\
\text { National Healthy Childhood Programme (NHCP)/Nurture } \\
\text { resources to ensure message consistency } \\
\text { o Brief verbal messages to be delivered in non-judgemental and } \\
\text { positive communication style, and in consideration of differing } \\
\text { individual parent needs } \\
\text { - HCP to provide parent with intervention resources (CHErlsH } \\
\text { leaflet, signposting to child health website, magnet with reminder } \\
\text { of verbal messages and infant bib signposting to child health website) } \\
\text { which provide further reinforcement regarding how to } \\
\text { perform behaviour } \\
\text { o Parent intervention resources to be developed using existing } \\
\text { HSE National Healthy Childhood Programme (NHCP)/Nurture } \\
\text { resources to ensure message consistency }\end{array}$ \\
\hline $\begin{array}{l}\text { Information about health } \\
\text { consequences }(5.1)\end{array}$ & $\begin{array}{l}\text { - HCP to provide parent with CHErlsH leaflet and child health website } \\
\text { (parent intervention resources) which will emphasize health } \\
\text { consequences of healthy infant feeding behaviours including } \\
\text { long-term health benefits }\end{array}$ \\
\hline $\begin{array}{l}\text { Information about social and } \\
\text { environmental } \\
\text { consequences (5.3) }\end{array}$ & $\begin{array}{l}\text { - HCP to provide parent with CHErlsH leaflet and child health website } \\
\text { (parent intervention resources) which will emphasize social and } \\
\text { environmental consequences of healthy infant feeding behaviours } \\
\text { including long-term cost and other benefits }\end{array}$ \\
\hline $\begin{array}{l}\text { Adding objects to the } \\
\text { environment }(12.5)\end{array}$ & $\begin{array}{l}\text { - HCP to provide parent with parent intervention resources including } \\
\text { a fridge magnet and an infant bib with reminder to provide further } \\
\text { reinforcement regarding how to perform behaviour }\end{array}$ \\
\hline $\begin{array}{l}\text { Restructuring the physical } \\
\text { environment }(12.1)\end{array}$ & $\begin{array}{l}\text { - HCP to provide parent with parent intervention resources including } \\
\text { a fridge magnet and an infant bib with reminder to provide further } \\
\text { reinforcement regarding how to perform behaviour }\end{array}$ \\
\hline Credible source (9.1) & $\begin{array}{l}\text { - HCP and intervention resources to emphasize credibility and } \\
\text { trustworthiness of intervention and associated resources both } \\
\text { verbally and through use of HSE National Healthy Childhood } \\
\text { Programme logos and branding }\end{array}$ \\
\hline Prompts, cues (7.I) & $\begin{array}{l}\text { - HCP to provide parent with magnet with reminder of verbal } \\
\text { messages and infant bib signposting to child health website (parent } \\
\text { intervention resources) which will act as prompt/cue for the } \\
\text { behaviour }\end{array}$ \\
\hline $\begin{array}{l}\text { HCP behaviour } \\
\text { Credible source }(9.1)\end{array}$ & $\begin{array}{l}\text { - CHErlsH researchers to deliver HCP training alongside senior } \\
\text { primary care dietician from the NHCP Nurture team and to } \\
\text { emphasize credibility and trustworthiness of training providers } \\
\text { (e.g., explicit mention of provider credentials and intervention } \\
\text { funding) and evidence-based intervention resources (e.g., HSE } \\
\text { Nurture website) } \\
\text { o HCP training to be embedded within existing } \\
\text { clinic CPD training schedule }\end{array}$ \\
\hline
\end{tabular}


Table 3. (Continued)

BCT selected in Step 7

Information about social and environmental consequences (5.3)

Information about health consequences (5.I)

Instruction on how to perform behaviour (4.I)

Demonstration of the behaviour (6.I)

Behavioural practice/ rehearsal (8.I)

Adding objects to the environment (12.5)

Restructuring the physical environment (I2.I)

Restructuring the social environment (12.2)
Operationalization of BCTs and modes of delivery within $\mathrm{CHErIsH}$

o HCP training to be developed using existing HSE National Healthy Childhood Programme (NHCP)/Nurture resources to ensure message consistency

- HCP training to highlight importance of the HCP as credible source for parents and for the importance of non-judgemental trusting relationships and communication between parent and HCPs

- Local practitioner representative (TH) to be used as local opinion leader to provide ongoing verbal support for the behaviour and influence other HCPs to deliver intervention

- HCP training and training resources (PowerPoint slides and HCP training manual) to emphasize (verbally and written) health, social, and environmental consequences of healthy infant feeding behaviours including long-term cost and social/environmental benefits

- HCPs to also be provided with parent intervention resources ( $\mathrm{CHErlsH}$ leaflet and child health website), which will emphasize social and environmental consequences of healthy infant feeding behaviours including long-term cost and other benefits

- HCP training and training resources to emphasize (verbally and written) health, social, and environmental consequences of healthy infant feeding behaviours including long-term health benefits

- HCPs to also be provided with parent intervention resources, which will emphasize health consequences of healthy infant feeding behaviours including long-term health benefits

- HCP training to advise HCPs on what verbal messages to provide at each time-point and how to do this in addition to provision of parent intervention resources

- HCP training to provide HCPs with an observable example of how to deliver brief verbal messages and intervention resources

- HCP training to prompt HCPs to practice delivery of verbal messages and intervention materials during the training, in order to increase habit and skill

- HCPs to be provided with training resources and $\mathrm{CHErlsH}$ poster with verbal messages on it for vaccination rooms as well as parent intervention resources to facilitate performance of the behaviour

- Automated computerized prompts to be used to remind HCP to deliver intervention at vaccination visits

- $\mathrm{CHErlsH}$ poster with verbal messages on it to be given to HCPs to put up in vaccination rooms

- Local primary care HCPs (e.g., PHNs, dieticians) beyond those delivering the intervention (GPs, PNs) to be made aware of the $\mathrm{CHErlsH}$ intervention to ensure clarity and consistency across $\mathrm{HCP}$ roles and intervention message

- On-site study administrator to provide ongoing technical support and assistance for HCPs via to facilitate delivery of intervention 
Table 3. (Continued)

\begin{tabular}{ll}
\hline BCT selected in Step 7 & $\begin{array}{l}\text { Operationalization of BCTs and modes of delivery } \\
\text { within CHErls }\end{array}$ \\
\hline Prompts/cues (7.I) & - Automated computerized prompts to be used to remind HCP \\
& to deliver intervention at vaccination visits \\
- CHErlsH poster with verbal messages on it to be given to HCPs & to put up in vaccination rooms to remind HCP to deliver \\
intervention at vaccination visits
\end{tabular}

$\mathrm{NHCP}=$ National Healthy Childhood Programme.

${ }^{\text {a }}$ Parent behaviour $=$ Parents to adhere to guideline-based early infant feeding practices between 0 and 2 years - Wait until as close to 26 weeks as possible to introduce solids (not before 17 weeks); Feed nutritious and developmentally suitable foods; Respond appropriately to child's hunger and satiety cues.; ${ }^{\mathrm{b}} \mathrm{HCP}$ behaviour $=\mathrm{GPs} / \mathrm{PNs}$ to provide guideline-based information and support regarding infant feeding and introduction of solid foods (0-2 years) in primary care during vaccination visits at $2,4,6,12$, 13 months.

\section{Phase 3: Identify content and implementation options}

\section{Step 7: Identify BCTS}

Using the BCW guidance (Michie et al., 2011), 11 potential BCTs were linked with intervention functions for the parent-level behaviour, and 15 potential BCTs were linked with the HCP-level behaviour (for full list of BCTs identified see File S3). For the parentlevel behaviour, we judged seven BCTs to meet the APEASE criteria that were selected for the intervention. For the HCP-level behaviour, we selected $10 \mathrm{BCTs}$, which met the APEASE criteria. Selected BCTs for both parent and HCP-level behaviours are provided in Table 2. Full details regarding the application of the APEASE criteria and rationale for decision-making regarding selection of BCTs are provided in File S2.

Step 8: Identify mode of delivery

Lastly, we integrated information from our evidence syntheses (SR1, SR2, SR3, QES1, QES2) and qualitative data collection (FG, QI) with recommendations from our practice and policy representatives (IC) and our international expert steering group (ISC). This guided our final decision-making on the operationalization and modes of delivery of BCTs within the CHErIsH intervention and implementation strategy. Full details are provided in Table 3.

For example, our informal consultations with policy representatives (IC) identified a number of existing resources that had been recently developed by the National Healthy Childhood Programme. These included a list of brief evidence-based infant feeding messages linked to all health service contact points between the ages of 0 and 2 (including vaccination visits) to ensure consistency of messages across health care providers, a child health website ('HSE MyChild.ie,'), and a number of online training modules for HCPs in relation to infant feeding. We decided to use content from these resources within our intervention to operationalize some of the BCTs identified in Step 7. For instance, we decided that the BCT 'Instruction on how to perform the behaviour' would be operationalized by having HCPs deliver brief infant feeding messages to parents on how to 


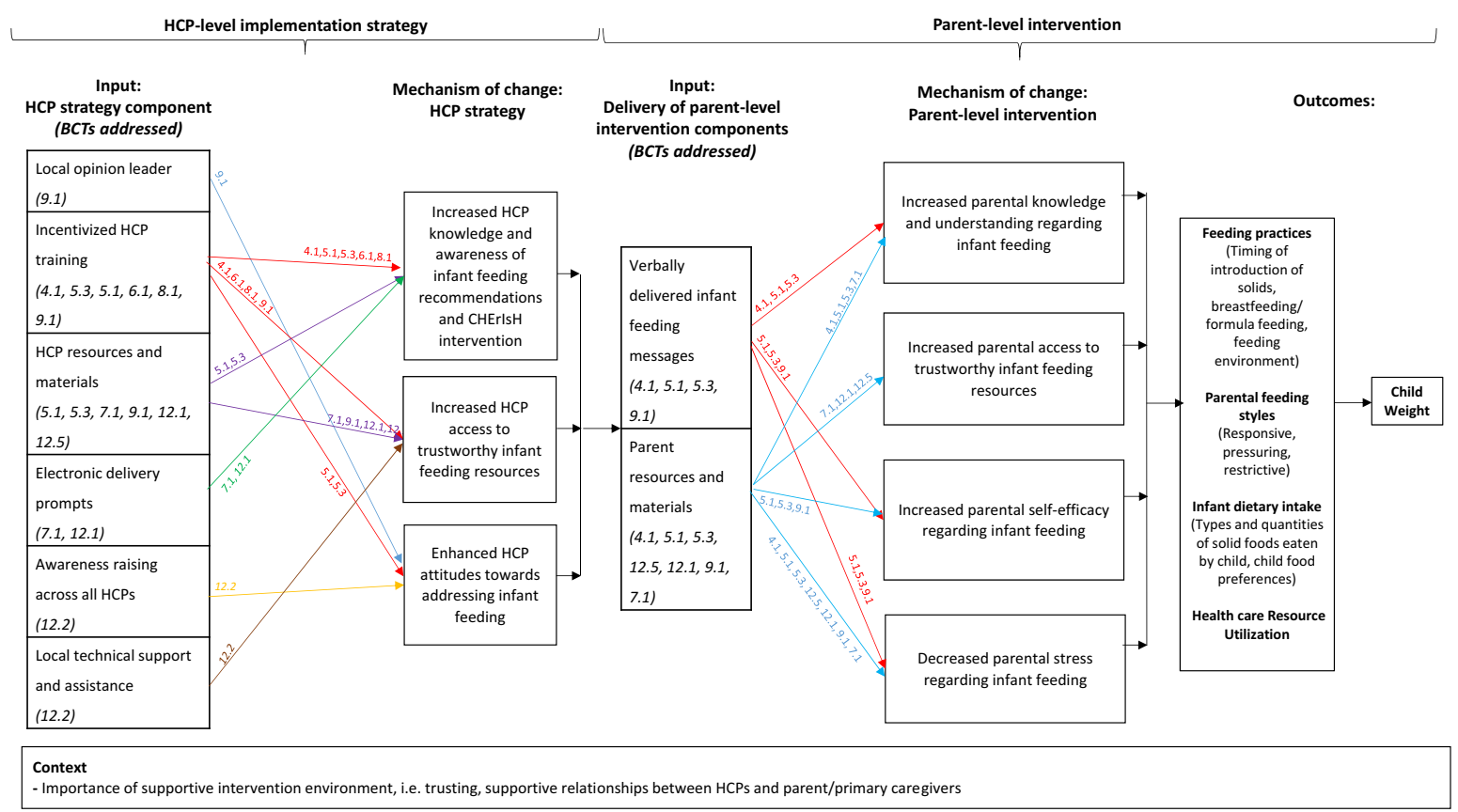

Figure I. Logic model of the finalized intervention. Numbers on arrows represent BCTs used to target specific mechanisms - these BCT numbers are explained in Tables 2 and 3; $\mathrm{HCPs}=$ health care professionals; $\mathrm{BCT}=$ behaviour change technique

perform the behaviour (e.g., responding to infant cues) at each vaccination time-point, in addition to signposting them to the child health website, which provided further information, resources, and reinforcement of the verbal messages. The exact wording and mode of delivery of the brief messages were informed by the findings of our systematic reviews of effectiveness (SR1) and theory use (SR3), our qualitative evidence syntheses (QES1, QES2), and qualitative data collection (FG, QI) in consultation with the practice and policy representatives (IC) to ensure alignment with existing National Healthy Childhood Programme messages. Likewise, we used content from existing National Healthy Childhood Programme training modules for HCPs relevant to our intervention to develop training and resources for HCPs as part of our implementation strategy, with the mode of delivery informed by findings of our systematic review of fidelity (SR2), qualitative evidence synthesis of HCP experiences of infant feeding interventions (QES2), and HCP interviews (QI).

The international steering committee expert meeting (ISC) identified three main recommendations for further consideration in finalizing the intervention components and mode of delivery. These related to (1) the involvement of primary care HCPs beyond the practice nurses and general practitioners who would be delivering the intervention, (2) the need for augmented HCP training beyond the existing National Healthy Childhood Programme online modules, and (3) the degree of flexibility/ tailoring permitted regarding the brief verbal messages. We reviewed these issues during a subsequent CHErIsH team meeting and decided to (1) ensure that all primary care and community-based HCPs within the relevant area were made aware of the intervention, (2) develop a group-based face-to-face training for HCPs utilizing the content from the existing online modules, and (3) ensure that the core intervention messages were kept consistent, but that the training would facilitate HCPs to deliver them in a flexible manner. 


\section{The finalized CHErlsH intervention and implementation strategy}

In brief, the finalized CHErIsH parent-level intervention consists of (1) verbally delivered brief infant feeding messages and (2) provision of additional infant feeding resources including an information leaflet, a magnet, an infant bib, and signposting to the National Healthy Childhood Programme child health information website. The intervention is to be delivered by the HCP providing the vaccination (i.e., practice nurse or GP) at the 2-, 4-, 6-, 12- and 13-month vaccination visits, just before the delivery of the vaccination. The finalized HCP-level implementation strategy to support delivery of the parent-level intervention consists of (1) A local opinion leader, (2) Incentivized HCP training, (3) Distribution of supporting HCP resources and educational materials, (4) Electronic delivery prompts for HCPs, (5) Awareness raising across all HCPs within the clinical practice and local primary care community, and (6) Provision of local technical support and assistance. Further details of the finalized intervention and implementation strategy including the brief messages and leaflet content are provided in File S3, and described using the TIDieR checklist in File S4. Figure 1 depicts the logic model for the intervention as recommended by Davidoff, Dixon-Woods, Leviton, and Michie (2015) to articulate and graphically represent the intervention structures, processes, and contextual factors intended to achieve the targeted aims and objectives.

\section{Discussion}

This study provides a unique example of the development of an empirically-based brief intervention aimed at improving parental infant feeding behaviours to prevent childhood obesity, alongside the concurrent development of an implementation strategy to support and sustain intervention delivery by HCPs within routine primary care settings. The study describes the use of the Behaviour Change Wheel approach to comprehensively and systematically integrate multiple sources of evidence to incorporate perspectives from policy, practice, research, and parent stakeholders.

It has been estimated that only approximately $14 \%$ of health care research gets implemented into practice (Gitlin, 2013; Green et al., 2009). As such, an earlier focus on sustainability, and development of interventions that are designed to be implementable and put into practice on a larger scale is warranted (Brownson et al., 2013; Curran et al., 2012; Glasgow et al., 2003). In order to do this, it is important to explicitly consider behavioural changes needed across multiple levels, and in particular, those of the HCPs needed to deliver interventions in health care settings. However, despite the importance of this, many interventions do not consider the broader implementation requirements from the outset, nor the specific HCP behaviours needed to facilitate the behaviour change at patient/individual level (Brownson et al., 2013; Toomey et al., 2018). A key strength of our study is its explicit focus on the behaviour change needed at a HCP level, and the strategies required to enable this, in order to facilitate the delivery of the intervention to parents. If the intervention proves to be feasible and effective, the development of a multi-faceted implementation strategy to be tested alongside the intervention itself provides us with a thorough, evidence-based strategy that will enable the translation of research findings into practice more rapidly.

The development of the CHErIsH intervention and implementation strategy was informed by a substantial number and variety of sources from multiple perspectives. This enabled a comprehensive approach to intervention development; however, integrating the findings from each of the sources was complicated, as was disentangling evidence 
from particular sources to determine exactly where they contributed. This process was further complicated by the fact that sources were often conducted in parallel due to time constraints, with findings combined iteratively throughout the course of the intervention development. However, the breadth and depth of sources used has resulted in an intervention and implementation strategy that is based on existing international evidence, but is also cognizant of local stakeholder needs and in alignment with national programmes and policy. The use of international experts from a variety of disciplines was also an important step and enabled us to develop an intervention that is informed by international learning and best practice; such that while developed in an Irish context, this study has broader international relevance. A CHErIsH patient and public involvement (PPI) group was also established and is described in the feasibility study protocol (Matvienko-Sikar et al., 2019). The purpose of this group was to advise on study design and data collection procedures including study questionnaires. This decision was taken to avoid overburdening the PPI group and minimize duplication of effort across the PPI group and parent focus groups detailed in this study, as these focus groups specifically explored parents' opinions of the proposed intervention to incorporate parent perspectives within the intervention development. However, it is acknowledged that the finalized intervention may have benefitted further from additional insights from the PPI group.

The Behaviour Change Wheel was used within this study to guide the development of both the parent-level intervention and the implementation strategy targeting HCP behaviour change in a thorough, transparent, and systematic way (Michie et al., 2011). Use of the $\mathrm{BCW}$ also enabled us to make the programme theory underlying both aspects of our intervention explicit, by facilitating our development of a logic model linking specific intervention components to study outcomes, via the intended mechanisms of change. While several other implementation frameworks or models could have used to develop the HCP-level implementation strategy (Nilsen, 2015), the BCW was specifically developed to improve the design and implementation of evidence-based practice (Michie et al., 2011) and has previously been used to develop implementation strategies to support the delivery of patient-level interventions (Gould et al., 2017; Mc Sharry, Murphy, \& Byrne, 2016; Sinnott et al., 2015). However, examples of studies that have used the Behaviour Change Wheel approach with this amount of evidence sources from such varied perspectives are rare; our study showcases the transparent and systematic development of a thorough and extremely comprehensive evidence-based intervention and associated implementation strategy. The transparency of this process will enable better testing of hypothesized causal pathways and facilitate future replication and/or refinement of the developed intervention.

\section{Implications for future research}

Childhood overweight and obesity is an extremely challenging public health issue, the aetiology of which is influenced by a complex interplay of multiple genetic, environmental, and lifestyle factors (Lytle, 2009; Sahoo et al., 2015). While there are a large number of factors which impact childhood obesity, the CHErIsH intervention provides an example of an evidence-based approach towards addressing one of these factors, and if successful will contribute an important piece to the overall puzzle. The next stages of this research are to evaluate the acceptability and feasibility of both the parent intervention and the HCP implementation strategy in a feasibility study (Matvienko-Sikar et al., 2019). This will facilitate the refinement of the intervention and its implementation strategy, and 
inform the next stages of the CHErIsH study, which will explore the effectiveness of both aspects.

\section{Conclusions}

This study provides a rigorous example of the development of an implementation strategy to facilitate HCP behaviour change, to support the implementation of an intervention aimed at improving parental adherence to recommended infant feeding behaviours. In addition, this study provides a unique example of integrating multiple different sources of evidence to guide the use of the BCW approach for multi-level behaviour change. As such, the transparency of the processes detailed in this paper will be of significant value for other researchers looking to accelerate findings into practice by planning for implementation from the outset, in a comprehensive and systematic manner.

\section{Acknowledgements}

The authors would like to thank and acknowledge the health care professionals and parents who took part in interviews and focus groups, members of our international expert steering committee, Dr Phil Jennings, Anne Pardy, and the HSE National Healthy Childhood Programme and Nurture Programme teams, Holly McGrath (University College Cork), Jennifer Cooney (University College Cork), Ruth Haugh (Mallow Primary Healthcare Centre) and staff of the Mallow Primary Healthcare Centre, Charlotte Griffin (University College Cork), and the entire CHErIsH study team.

\section{Conflicts of interest}

All authors declare no conflict of interest.

\section{Funding}

The CHErIsH study is funded by the Health Research Board of Ireland; award number ICE2015-1026.

\section{Author contribution}

Elaine Toomey (Conceptualization; Formal analysis; Investigation; Methodology; Visualization; Writing - original draft; Writing - review \& editing): Karen Matvienko-Sikar (Conceptualization; Formal analysis; Methodology; Resources; Visualization; Writing original draft; Writing - review \& editing): Edel Doherty (Conceptualization; Funding acquisition; Methodology; Supervision): Janas Harrington (Conceptualization; Funding acquisition; Supervision; Visualization; Writing - original draft; Writing - review \& editing): Catherine B Hayes (Conceptualization; Funding acquisition; Supervision; Visualization; Writing - original draft; Writing - review \& editing): Caroline Heary (Conceptualization; Funding acquisition; Supervision; Visualization; Writing - original draft; Writing - review \& editing): Marita Hennessy (Conceptualization; Visualization; Writing - original draft; Writing - review \& editing): Colette Kelly (Conceptualization; Funding acquisition; Supervision; Visualization; Writing - original draft; Writing - review \& editing): Sheena McHugh (Conceptualization; Funding acquisition; Methodology; 
Visualization; Writing - original draft; Writing - review \& editing): Jenny McSharry (Conceptualization; Funding acquisition; Visualization; Writing - original draft; Writing review \& editing): Joanne O'Halloran (Methodology; Resources; Writing - original draft; Writing - review \& editing): Michelle Queally (Conceptualization; Investigation; Methodology; Visualization; Writing - original draft; Writing - review \& editing): Tony Heffernan (Conceptualization; Project administration; Resources; Visualization; Writing original draft; Writing - review \& editing): Patricia M Kearney (Conceptualization; Formal analysis; Funding acquisition; Investigation; Methodology; Project administration; Supervision; Visualization; Writing - original draft; Writing - review \& editing): Molly Byrne (Conceptualization; Formal analysis; Funding acquisition; Investigation; Methodology; Supervision; Visualization; Writing - original draft; Writing - review \& editing).

\section{Data availability statement}

Data sharing is not applicable to this article as no new data were created or analysed in this study.

\section{References}

Barrera, C. M., Hamner, H. C., Perrine, C. G., \& Scanlon, K. S. (2018). Timing of introduction of complementary foods to US infants, national health and nutrition examination survey 20092014. Journal of the Academy of Nutrition and Dietetics, 118, 464-470. https://doi.org/10. 1016/j.jand.2017.10.020

Bennett, A. (2017). Maternal and paternal influences on infant diet and growth throughout the first year of life. (Doctor of Philosophy), Dublin Institute of Technology.

Birch, LL., \& Doub, AE. (2014). Learning to eat: Birth to age 2 y. American Journal of Clinical Nutrition, 99, 723S-728S. https://doi.org/10.3945/ajcn.113.069047

Blake-Lamb, T. L., Locks, L. M., Perkins, M. E., Woo Baidal, J. A., Cheng, E. R., \& Taveras, E. M. (2016). Interventions for childhood obesity in the first 1,000 days a systematic review. American Journal of Preventive Medicine, 50, 780-789. https://doi.org/10.1016/j.amepre.2015.11.010

Borrelli, B., Sepinwall, D., Ernst, D., Bellg, A. J., Czajkowski, S., Breger, R., . . Orwig, D. (2005). A new tool to assess treatment fidelity and evaluation of treatment fidelity across 10 years of health behavior research. Journal of Consulting and Clinical Psychology, 73, 852-860. https://doi. org/10.1037/0022-006X.73.5.852

Bourgeois, N., Brauer, P., Simpson, J. R., Kim, S., \& Haines, J. (2016). Interventions for prevention of childhood obesity in primary care: A qualitative study. CMAJ open, 4(2), E194-E199. https://doi. org/10.9778/cmajo.20150081

Brown, C. H., \& Beardslee, W. (2016). Realizing population-level improvements for all children's cognitive, affective, and behavioral health: Introduction to the special issue. American Journal of Preventive Medicine, 51, S101-S105. https://doi.org/10.1016/j.amepre.2016.07.017

Brownson, R. C., Jacobs, J. A., Tabak, R. G., Hoehner, C. M., \& Stamatakis, K. A. (2013). Designing for dissemination among public health researchers: Findings from a national survey in the United States. American Journal of Public Health, 103, 1693-1699. https://doi.org/10.2105/AJPH. 2012.301165

Castro, P. D., Kearney, J., \& Layte, R. (2015). A study of early complementary feeding determinants in the Republic of Ireland based on a cross-sectional analysis of the Growing Up in Ireland infant cohort. Public Health Nutr, 18, 292-302. https://doi.org/10.1017/s1368980014000329

Chambers, D. A., \& Norton, W. E. (2016). The adaptome: Advancing the science of intervention adaptation. American Journal of Preventive Medicine, 51(Suppl 2), S124-S131. https://doi. org/10.1016/j.amepre.2016.05.011 
Clayton, H. B., Li, R., Perrine, C. G., \& Scanlon, K. S. (2013). Prevalence and reasons for introducing infants early to solid foods: Variations by milk feeding type. Pediatrics, 131, e1108-e1114. https://doi.org/10.1542/peds.2012-2265

Cottrell, E., Whitlock, E., Kato, E., Uhl, S., Belinson, S., Chang, C., Guise, J. M. (2014). AHRQ methods for effective bealth care defining the benefits of stakeholder engagement in systematic reviews. Rockville, MD: Agency for Healthcare Research and Quality (US).

Curran, G. M., Bauer, M., Mittman, B., Pyne, J. M., \& Stetler, C. (2012). Effectiveness-implementation hybrid designs: Combining elements of clinical effectiveness and implementation research to enhance public health impact. Medical Care, 50, 217-226. https://doi.org/10.1097/MLR.0b $013 \mathrm{e} 3182408812$

Davidoff, F., Dixon-Woods, M., Leviton, L., \& Michie, S. (2015). Demystifying theory and its use in improvement. BMJ Quality \& Safety, 24, 228-238. https://doi.org/10.1136/bmjqs-2014-003627

Deverka, P. A., Lavallee, D. C., Desai, P. J., Esmail, L. C., Ramsey, S. D., Veenstra, D. L., \& Tunis, S. R. (2012). Stakeholder participation in comparative effectiveness research: Defining a framework for effective engagement. Journal of comparative effectiveness research, 1, 181-194. https:// doi.org/10.2217/cer.12.7

Fewtrell, M., Bronsky, J., Campoy, C., Domellof, M., Embleton, N., Fidler Mis, N., ... Molgaard, C. (2017). Complementary feeding: A position paper by the european society for paediatric gastroenterology, hepatology, and nutrition (ESPGHAN) committee on nutrition. Journal of Pediatric Gastroenterology and Nutrition, 64(1), 119-132. https://doi.org/10.1097/mpg. 0000000000001454

Food Safety Authority of Ireland (2011). Best Practice for Infant Feeding in Ireland: From preconception through the first year of an infant's life. Dublin, Ireland: Author.

Gitlin, L. N. (2013). Introducing a new intervention: An overview of research phases and common challenges. American Journal of Occupational Therapy, 67, 177-184. https://doi.org/10. 5014/ajot.2013.006742

Glasgow, R., Lichtenstein, E., \& Marcus, A. (2003). Why don't we see more translation of health promotion research to practice? Rethinking the efficacy-to-effectiveness transition. American Journal of Public Health, 93, 1261-1267.

Gould, G. S., Bar-Zeev, Y., Bovill, M., Atkins, L., Gruppetta, M., Clarke, M. J., \& Bonevski, B. (2017). Designing an implementation intervention with the Behaviour Change Wheel for health provider smoking cessation care for Australian Indigenous pregnant women. Implementation Science, 12(1), 114. https://doi.org/10.1186/s13012-017-0645-1

Grant, J., Green, L., \& Mason, B. (2003). Basic research and health: A reassessment of the scientific basis for the support of biomedical science. Research Evaluation, 12, 217-224. https://doi.org/ $10.3152 / 147154403781776618$

Graziose, M. M., Downs, S. M., O'Brien, Q., \& Fanzo, J. (2017). Systematic review of the design, implementation and effectiveness of mass media and nutrition education interventions for infant and young child feeding. Public Health Nutrition, 21, 273-287. https://doi.org/10.1017/ S1368980017002786

Green, L. W., Ottoson, J. M., García, C., \& Hiatt, R. A. (2009). Diffusion theory and knowledge dissemination, utilization, and integration in public health. Annual Review of Public Health, 3O(1), 151-174. https://doi.org/10.1146/annurev.publhealth.031308.100049

Health Service Executive (2016). Nutrition Reference Pack for Infants (0-12 months). Wicklow, Ireland: Community Nutrition and Dietetic Service, Community Healthcare Organisation Area 6.

Healthy Ireland (2015). Feeding your baby: Introducing family meals. Dublin, Ireland: Author.

Hesketh, K. D., \& Campbell, K. J. (2010). Interventions to prevent obesity in 0-5 year olds: An Updated systematic review of the literature. Obesity, 18(S1), S27-S35. https://doi.org/10.1038/ oby.2009.429

Horodynski, M., Olson, B., Arndt, M. J., Brophy-Herb, H., Shirer, K., \& Shemanski, R. (2007). Lowincome mothers' decisions regarding when and why to introduce solid foods to their infants: Influencing factors. Journal of Community Health Nursing, 24, 101-118. https://doi.org/10. 1080/07370010701316247 
HSE Healthy Childhood Programme. Retrieved from https://www.hse.ie/eng/about/who/healthwe llbeing/our-priority-programmes/child-health-and-wellbeing/

HSE MyChild.ie. Retrieved from www.mychild.ie

HSE Nurture Programme - Infant Health and Wellbeing. Retrieved from https://www.hse.ie/eng/hea lth/child/nurture/

Hurley, K. M., Cross, M. B., \& Hughes, S. O. (2011). A systematic review of responsive feeding and child obesity in high-income countries. The Journal of Nutrition, 141, 495-501. https://doi. org/10.3945/jn. 110.130047

Inoue, M., \& Binns, C. W. (2014). Introducing solid foods to infants in the Asia Pacific region. Nutrients, 6(1), 276-288. https://doi.org/10.3390/nu6010276

Iwelunmor, J., Blackstone, S., Veira, D., Nwaozuru, U., Airhihenbuwa, C., Munodawafa, D., ... Ogedegebe, G. (2016). Toward the sustainability of health interventions implemented in subSaharan Africa: A systematic review and conceptual framework. Implementation Science: IS, 11 , 43-43. https://doi.org/10.1186/s13012-016-0392-8

Laws, R., Campbell, K. J., van der Pligt, P., Russell, G., Ball, K., Lynch, J., . . Denney-Wilson, E. (2014). The impact of interventions to prevent obesity or improve obesity related behaviours in children (0-5 years) from socioeconomically disadvantaged and/or indigenous families: A systematic review. BMC Public Health, 14(779). https://doi.org/10.1186/1471-2458-14-779

Leslie, L. K., Mehus, C. J., Hawkins, J. D., Boat, T., McCabe, M. A., Barkin, S., \& Beardslee, W. (2016). Primary health care: Potential home for family-focused preventive interventions. American Journal of Preventive Medicine, 51(Suppl 2), S106-S118. https://doi.org/10.1016/j.amepre. 2016.05.014

Lytle, L. A. (2009). Examining the etiology of childhood obesity: The IDEA study. American Journal of Community Psychology, 44, 338-349. https://doi.org/10.1007/s10464-009-9269-1

Matvienko-Sikar, K., Kelly, C., Sinnott, C., McSharry, J., Houghton, C., Heary, C., .. Kearney, P. M. (2018). Parental experiences and perceptions of infant complementary feeding: A qualitative evidence synthesis. Obesity Reviews, 19, 501-517. https://doi.org/10.1111/obr.12653

Matvienko-Sikar, K., Toomey, E., Delaney, L., Flannery, C., McHugh, S., McSharry, J., . . Kearney, P. M. (2019). Behaviour change techniques and theory use in healthcare professional-delivered infant feeding interventions to prevent childhood obesity: A systematic review. Health Psychology Review, 13, 277-294. https://doi.org/10.1080/17437199.2019.1605838

Matvienko-Sikar, K., Toomey, E., Delaney, L., Harrington, J., Byrne, M., \& Kearney, P. M. (2018). Effects of healthcare professional delivered early feeding interventions on feeding practices and dietary intake: A systematic review. Appetite, 123, 56-71. https://doi.org/10.1016/j.appet.2017.12.001

Mc Sharry, J., Murphy, P. J., \& Byrne, M. (2016). Implementing international sexual counselling guidelines in hospital cardiac rehabilitation: Development of the CHARMS intervention using the Behaviour Change Wheel. Implementation Science, 11(1), 134. https://doi.org/10.1186/ s13012-016-0493-4

McPherson, M. E., Mirkin, R., Heatherley, P. N., \& Homer, C. J. (2012). Educating health care professionals in advocacy for childhood obesity prevention in their communities: Integrating public health and primary care in the Be Our Voice project. American Journal of Public Health, 102, e37-e43. https://doi.org/10.2105/AJPH.2012.300833

Michie, S., Atkins, L., \& West, R. (2014). The Behaviour change wheel: A guide to designing interventions. London, UK: Silverback Publishing.

Michie, S., \& Prestwich, A. (2010). Are interventions theory-based? Development of a theory coding scheme. Health Psychology, 29(1), 1-8. https://doi.org/10.1037/a0016939

Michie, S., Richardson, M., Johnston, M., Abraham, C., Francis, J., Hardeman, W., ... Wood, C. E. (2013). The behavior change technique taxonomy (v1) of 93 Hierarchically clustered techniques: Building an international consensus for the reporting of behavior change interventions. Annals of Behavioral Medicine, 46(1), 81-95. https://doi.org/10.1007/ s12160-013-9486-6 
Michie, S., van Stralen, M. M., \& West, R. (2011). The behaviour change wheel: A new method for characterising and designing behaviour change interventions. Implementation Science: IS, 6 , 42-42. https://doi.org/10.1186/1748-5908-6-42

Morris, Z. S., Wooding, S., \& Grant, J. (2011). The answer is 17 years, what is the question: Understanding time lags in translational research.Journal of the Royal Society of Medicine, 104, 510-520. https://doi.org/10.1258/jrsm.2011.110180

Nilsen, P. (2015). Making sense of implementation theories, models and frameworks. Implementation Science, 10(53). https://doi.org/10.1186/s13012-015-0242-0

O'Donovan, S. M., Murray, D. M., Hourihane, J. O., Kenny, L. C., Irvine, A. D., \& Kiely, M. (2015). Adherence with early infant feeding and complementary feeding guidelines in the Cork BASELINE Birth Cohort Study. Public Health Nutrition, 18, 2864-2873. https://doi.org/10. $1017 / \mathrm{s} 136898001500018 \mathrm{x}$

Patro-Gołąb, B., Zalewski, B. M., Kołodziej, M., Kouwenhoven, S., Poston, L., Godfrey, K. M., ... Szajewska, H. (2016). Nutritional interventions or exposures in infants and children aged up to 3 years and their effects on subsequent risk of overweight, obesity and body fat: A systematic review of systematic reviews. Obesity Reviews, 17, 1245-1257. https://doi.org/10.1111/obr. 12476

Pearce, J., \& Langley-Evans, S. C. (2013). The types of food introduced during complementary feeding and risk of childhood obesity: A systematic review. International Journal of Obesity, 37, 477-485. https://doi.org/10.1038/ijo.2013.8

Pluye, P., Potvin, L., \& Denis, J.-L. (2004). Making public health programs last: Conceptualizing sustainability. Evaluation and Program Planning, 27, 121-133. https://doi.org/10.1016/j.eva lprogplan.2004.01.001

Pluymen, L. P. M., Wijga, A. H., Gehring, U., Koppelman, G. H., Smit, H. A., \& van Rossem, L. (2018). Early introduction of complementary foods and childhood overweight in breastfed and formulafed infants in the Netherlands: The PIAMA birth cohort study. European Journal of Nutrition, 57, 1985-1993. https://doi.org/10.1007/s00394-018-1639-8

Power, J., Gilmore, B., Vallières, F., Toomey, E., Mannan, H., \& McAuliffe, E. (2019). Adapting health interventions for local fit when scaling-up: A realist review protocol. British Medical Journal Open, 9(1), e022084. https://doi.org/10.1136/bmjopen-2018-022084

Proctor, E., Luke, D., Calhoun, A., McMillen, C., Brownson, R., McCrary, S., \& Padek, M. (2015). Sustainability of evidence-based healthcare: Research agenda, methodological advances, and infrastructure support. Implementation Science: IS, 10, 88-88. https://doi.org/10.1186/ s13012-015-0274-5

Redsell, S.A., Edmonds, B., Swift, J.A., Siriwardena, A.N. Weng, S., Nathan, D., \& Glazebrook, C. (2016). Systematic review of randomised controlled trials of interventions that aim to reduce the risk, either directly or indirectly, of overweight and obesity in infancy and early childhood. Maternal and Child Nutrition, 12(1), 24-38.

Safefood (2018). What parents think about weaning: An island of Ireland study. Cork, Ireland: Author.

Sahoo, K., Sahoo, B., Choudhury, A. K., Sofi, N. Y., Kumar, R., \& Bhadoria, A. S. (2015). Childhood obesity: causes and consequences. Journal of Family Medicine and Primary Care, 4, 187-192. https://doi.org/10.4103/2249-4863.154628

Schell, S. F., Luke, D. A., Schooley, M. W., Elliott, M. B., Herbers, S. H., Mueller, N. B., \& Bunger, A. C. (2013). Public health program capacity for sustainability: A new framework. Implementation Science, 8(15). https://doi.org/10.1186/1748-5908-8-15

Schiess, S., Grote, V., Scaglioni, S., Luque, V., Martin, F., Stolarczyk, A., ... Koletzko, B. (2010). Introduction of complementary feeding in 5 European countries. Journal of Pediatric Gastroenterology and Nutrition, 50(1), 92-98. https://doi.org/10.1097/MPG.0b013e31819f $1 \mathrm{ddc}$

Singh, A. S., Mulder, C., Twisk, J. W., van Mechelen, W., \& Chinapaw, M. J. (2008). Tracking of childhood overweight into adulthood: A systematic review of the literature. Obesity Reviews, 9 , 474-488. https://doi.org/10.1111/j.1467-789X.2008.00475.x 
Sinnott, C., Mercer, S. W., Payne, R. A., Duerden, M., Bradley, C. P., \& Byrne, M. (2015). Improving medication management in multimorbidity: Development of the MultimorbiditY COllaborative medication review and decision making (MY COMRADE) intervention using the Behaviour Change Wheel. Implementation Science: IS, 10, 132-132. https://doi.org/10.1186/s13012-0150322-1

Stevens, J., Pratt, C., Boyington, J., Nelson, C., Truesdale, K. P., Ward, D. S., . . Murray, D. M. (2017). Multilevel interventions targeting obesity: Research recommendations for vulnerable populations. American Journal of Preventive Medicine, 52(1), 115-124. https://doi.org/10. 1016/j.amepre.2016.09.011

Tarrant, R. C., Younger, K. M., Sheridan-Pereira, M., White, M. J., \& Kearney, J. M. (2010). Factors associated with weaning practices in term infants: A prospective observational study in Ireland. British Journal of Nutrition, 104, 1544-1554. https://doi.org/10.1017/S0007114510002412

Toomey, E., Matvienko-Sikar, K., Heary, C., Delaney, L., Queally, M., Hayes, B.C . . Choosing Healthy Eating for Infant Health study, $\mathrm{t}$ (2018). Intervention fidelity within trials of infant feeding behavioral interventions to prevent childhood obesity: A systematic review. Annals of Behavioral Medicine, 53(1), 75-97. https://doi.org/10.1093/abm/kay021

Walugembe, D. R., Sibbald, S., Le Ber, M. J., \& Kothari, A. (2019). Sustainability of public health interventions: Where are the gaps? Health Research Policy and Systems, 17(1), 8. https://doi. org/10.1186/s12961-018-0405-y

Wang, J., Wu, Y., Xiong, G., Chao, T., Jin, Q., Liu, R., .. Yang, X. (2016). Introduction of complementary feeding before 4 months of age increases the risk of childhood overweight or obesity: A meta-analysis of prospective cohort studies. Nutrition Research, 36, 759-770. https://doi.org/10.1016/j.nutres.2016.03.003

Waters, E., de Silva-Sanigorski, A., Burford, B., Brown, T., Campbell, K., Gao, Y., ... Summerbell, C. (2011). Interventions for preventing obesity in children. Cochrane Database Of Systematic Reviews, (12), CD001871. https://doi.org/10.1002/14651858.CD001871.pub3

Woo Baidal, J. A., Locks, L. M., Cheng, E. R., Blake-Lamb, T. L., Perkins, M. E., \& Taveras, E. M. (2016). Risk factors for childhood obesity in the first 1,000 days: A Systematic review. American Journal of Preventive Medicine, 50, 761-779. https://doi.org/10.1016/j.amepre.2015.11.012

World Health Organisation (2002) Infant and young child nutrition: Global strategy on infant and young child feeding. Geneva, Switzerland: Author.

Received 23 September 2019; revised version received 10 January 2020

\section{Supporting Information}

The following supporting information may be found in the online edition of the article:

File S1. Selection of intervention functions.

File S2. Selection of behaviour change techniques (BCTs).

File S3. Finalised CHErIsH parent-level intervention and HCP implementation strategy.

File S4. Description of the finalised intervention and implementation strategy using the TIDieR checklist. 